\title{
REDUCED MODEL FOR THE THERMO-FLUID DYNAMIC ANALYSIS OF A POWER TRANSFORMER RADIATOR WORKING IN ONAF MODE
}

\author{
Luciano Garelli ${ }^{\mathrm{a}}$, Gustavo Ríos Rodriguez ${ }^{\mathrm{a}}$, Mario Storti ${ }^{\mathrm{a}}$, Daniel Granata ${ }^{\mathrm{b}}$, Mauro \\ Amadei $^{\mathrm{b}}$ and Marcelo Rossetti ${ }^{\mathrm{b}}$ \\ ${ }^{a}$ Centro de Investigación de Métodos Computacionales, CIMEC (UNL - CONICET), 3000 Santa Fe, \\ Argentina., Tel.: +54 (0) 3424511594 Fax: +54 (0) 3424511595 , \\ ${ }^{\mathrm{b}}$ Tadeo Czerweny S.A, 2252 Gálvez, Santa Fe, Argentina., Tel.: +54 (0) 3404487200 Fax: +54 (0) \\ 3404483330
}

\begin{abstract}
This work introduces an extension of the semi-analytical reduced model presented in G. Ríos Rodriguez et.al., App Thermal Eng, 112:1271-1280 (2016); with the aim of analyzing the thermo-fluid dynamic behavior of a power transformer radiator working in ONAF (Oil Natural Air Forced) mode, considering vertical blowing of the fans. The objective of this research paper is the development of a numerical tool to be used during the design process of power transformers in order to obtain more detailed information about the radiators performance, either they are working in ONAF or ONAN (Oil Natural Air Natural) mode. Since it is observed both in the experimental measurements and in the numerical simulations that not all the radiator panels are blown by a single fan, the reduced model here presented considers a mixed situation wherein the heat is removed by natural convection in a fraction of the radiator while in the rest the heat is removed by forced convection. As a consequence, besides adding to the set of conservation equations introduced in G. Ríos Rodriguez et.al., App Thermal Eng, 112:12711280 (2016); those corresponding to the momentum and energy balance for considering forced heat convection transfer, there appears the need of introducing additional equations for coupling the natural and forced heat convection transfer models. The reduced model developed in this work is applied to estimate different characteristic parameters of a power transformer radiator working in ONAF mode, like the oil flow rate, dissipated power, outlet and inlet oil temperatures, among others. The computed results are compared to those obtained by CFD simulations and experimental measurements carried out on an ad-hoc workbench for validation purposes. It is found that the reduced model reproduces with acceptable accuracy the values of the most important design variables at a very low computation cost. In this manner, it can be considered as a reliable and valuable tool in the design of power transformers, allowing to carry out parametric studies.
\end{abstract}


Keywords: Power Transformer, Computational Fluid Dynamics, Experimental Measurements, Heat Dissipation, ONAF

\section{INTRODUCTION}

It is known that several sources of heat generation (losses) exists in power transformers (Vecchio et al., 2001), i.e. hysteresis and eddy currents among others, but the most important comes from the cooper (resistive) losses caused by the main currents due to Joule heating or $I^{2} \cdot R$, where $I$ is the current intensity and $R$ the winding resistance. Wherewith, for a given current intensity and environmental conditions the radiators must be able to dissipate the generated heat without exceeding the permissible temperature limits imposed in the certification process of the machine. If this limits are exceeded, damage in the insulation may occur thus reducing the operative life of the transformer. One of the most common ways to enhance the heat dissipation is to use fans for increasing the air flow between the radiator fins or panels, providing better cooling capacity than that supplied by natural convection. The fans are mounted near the radiators and when the temperature exceeds a prescribed limit they are turned on. Also, under the same environmental conditions a power transformer working in ONAF mode can be used under a higher current load than if it were working in ONAN, without exceeding the design temperature limits. This increase in the transformer load can arise from particular situations like the failure of another transformer, the increase in the current consumption due to hot weather conditions, etc. In this context, several studies have been conducted in the last years with the aim of evaluating and improving the cooling capacity of power transformers working in ONAF mode.

In Kim et al. (2013) it is presented a numerical prediction and experimental studies about the cooling capacity of an oil-filled power transformer working both in ONAN and OFAN (Oil Forced Air Natural), considering that the excessive heat generation is the major cause of insulation deterioration. The experimental results show a cooling capacity increase of $7 \%$ when the oil flow rate is four times that in the ONAN mode, whereas the CFD (Computational Fluid Dynamics) results show an increase of $17 \%$. These results are also in agreement with those presented in Karsai et al. (1987), where it is mentioned that the application of forced oil flow is only feasible in some justifiable conditions and only if it is combined with an efficient convective heat transfer in the radiators. In order to improve the cooling capacity, it is also important to consider the blowing direction of the fans. This is studied in detail in Paramane et al. (2014), where numerical and experimental analysis are carried out both for horizontal and vertical blowing directions. Therein, it is found for a specific transformer, that the horizontal blowing direction has higher efficiency than the vertical one due to less sideways leakage of the air. The cooling capacity increases from $19.7[\mathrm{Kw}]$ in ONAN to 65-85 [Kw] in ONAF, depending on the configuration and blowing direction of the fans. More recently, Paramane et al. (2016) studied both the internal oil flow and the external air flow using a coupled thermo-fluid dynamic model for numerical simulations as well as experimental data. They consider for the analysis a power transformer with a five radiator arrangement, each radiator fitted with 27 fins of $2.5[\mathrm{~m}]$ height and $0.52[\mathrm{~m}]$ width, with a spacing of 0.05 [m] between fins. The oil inlet conditions (mass flow rate and temperature) are obtained experimentally and different (vertical and horizontal) blowing directions are studied. The numerical simulation of each coupled thermo-hydraulic problem requires approximately 500 hours ( $\sim 21$ days) on eight parallel processors. It is found, in the case of vertical blowing, that the central radiator dissipates $15 \%$ less heat compared to the end radiators, whereas in horizontal blowing there is a monotonic decrease in heat dissipation from the first towards the last radiator. For that configuration, it is concluded that horizontal 
blowing helps to dissipate $6.1 \%$ more heat than vertical blowing (Paramane et al., 2016).

As can be seen, an important effort has been put into studying the operation conditions of radiators in ONAF mode using CFD simulations and experimental measurements. CFD simulations based on the Finite Volume Method (FVM) or the Finite Element Method (FEM) have shown to be reliable and accurate tools to describe the behavior of the radiator and the windings for different working conditions (Kim et al., 2013; Paramane et al., 2014, 2016; El Wakil et al., 2006; Tsili et al., 2012; Torriano et al., 2012; Nabati et al., 2009; Gastelurrutia et al., 2011). A detailed description of the temperature distribution on each radiator panel, as well as the air and oil flows, can be obtained. However, these simulations are usually very expensive from the computational point of view and they also need accurate information from experimental measurements in order to properly set the initial / boundary conditions, like the inlet oil mass flow rate and the inlet oil temperature. Also, the simulation of the coupled thermo-hydrodynamics of the complete transformer (oil tank, windings, radiators, etc.) is a very difficult task when considering the processes of building the geometric model with all its details and thereafter the mesh generation. For this reason, in this research article a reduced model is presented with the objective of being able to evaluate the performance of a power transformer during the design and development stages without requiring the generation and modification of complex FVM or FEM models, which can be generated later on an advanced preliminary design.

In this work an extension of the semi-analytical reduced model presented in Ríos Rodriguez et al. (2016) is introduced, with the aim of providing a low cost computational tool able to analyze the coupled thermo-fluid dynamic behavior of a power transformer radiator working in ONAF mode and considering vertical blowing of the fans. The objective of the reduced model is to be used as a numerical tool during the design process of a power transformer, supplying crucial information of global design parameters at a relatively low cost, thus allowing to test different working conditions and configurations which can also be used as input data for subsequent CFD analysis. The paper presents a thermal and fluid flow analysis of a 30MVA - 132/34.5/13.8kV power transformer radiator manufactured by Tadeo Czerweny S.A. company. The study is mainly focused on the heat dissipated within the radiators assuming that the power transformer is working in ONAF mode. The analysis is carried out by first considering analytical calculations, then CFD simulations and finally experimental data acquired from measurements using an ad-hoc transformer workbench. As in Ríos Rodriguez et al. (2016), the computation of various flow and thermal characteristic parameters of the cooling circuit is addressed by means of an extended reduced model. The solution of this coupled system of equations delivers information about several variables (oil temperature at the inlet and outlet ducts of the radiator, the oil flow rate, the air temperature and its mean velocity, among others).

The corresponding CFD simulations are presented following the guidelines introduced in Ríos Rodriguez et al. (2016). Turbulence of the air flow in the radiator is taken into account in the simulations using a Large Eddy Simulation (LES) model. The dissipated heat, the oil flow rate and the air velocity distribution along the radiator are compared to those experimentally measured.

The experimental measurements are carried out on a workbench specifically dedicated to this end at Tadeo Czerweny S.A. company (a detailed description can be seen in Ríos Rodriguez et al. (2016)). This workbench enables to validate the calculated values by performing measurements in controlled conditions. Temperature distribution on the fin surface, oil temperature at the inlet and outlet headers of the radiator, oil flow rate as well as air temperature and velocity distributions are measured. The encountered differences among the reduced model, the CFD simulation and the experimental results are discussed. Finally, future research work is 
briefly described with the aim of improving the heat dissipation in the radiators.

\section{EXTENDED REDUCED MODEL - ANALYTICAL DESCRIPTION}

The reduced model here presented is an extension of that introduced in Ríos Rodriguez et al. (2016) for the ONAN case. The new model allows to calculate the cooling capacity of a radiator working in both ONAN and ONAF operative conditions. It is based on a set of coupled analytical equations of momentum and energy balance for the oil running through the radiator channels, for the air flowing between the radiator panels and also for the heat being conducted through the surface of the panels. In some instances, when a radiator is working in ONAF, and depending on its size, it is observed that not all the fins are being blown by the fan (Paramane et al., 2016). A certain number of radiator fins are dissipating heat in forced convection condition while the rest are working in natural convection. As a consequence, the extended reduced model introduced in this work will consider both types of heat convection models and will couple them with a suitable set of additional equations. First, for the sake of clarity, we consider each convection condition separately.

\subsection{Natural convection}

A set of five coupled equations are required in the case of natural convection to obtain the oil flow rate $\left(Q_{o i l_{N}}\right)$, the inlet $\left(T_{o i l_{2 N}}\right)$ and outlet $\left(T_{o i l_{1 N}}\right)$ oil temperatures, the outlet $\left(T_{a i r_{2 N}}\right)$ air temperature and the air mean velocity $\left(U_{\text {air }}\right)$ for a given power $(P)$ to be dissipated. This set of equations can be expressed as residuals in the following manner

- Oil momentum balance

$$
R_{m o m, o i l}\left(T_{o i l_{1 N}}, T_{o i l_{2 N}}, Q_{o i l_{N}}\right)=0
$$

- Oil energy balance

$$
R_{e n e r, o i l}\left(T_{o i l_{1 N}}, T_{o i l_{2 N}}, Q_{o i l_{N}}\right)=0
$$

- Air momentum balance

$$
R_{\text {mom,air }}\left(T_{a i r_{2 N}}, U_{\text {air }}\right)=0
$$

- Air energy balance

$$
R_{\text {ener,air }}\left(T_{\text {air } 2 N}, U_{\text {air }}\right)=0
$$

- Energy balance between the oil and the air

$$
R_{h e x}\left(T_{\text {oil }_{1 N}}, T_{\text {oil }_{2 N}}, T_{\text {air }_{2 N}}, U_{\text {air }}, Q_{\text {oil }_{N}}\right)=0
$$

The derivation of the previous equations are described in detail in Ríos Rodriguez et al. (2016).

\subsection{Forced convection}

If the heat dissipation in forced convection condition is considered, the resulting system of equations is reduced to four since the air momentum balance equation is removed. This is so because the air velocity $\left(U_{\text {air }}\right)$ is a prescribed value for the ONAF model. Then, the following set of equations allows to obtain the oil flow rate $\left(Q_{o i l_{F}}\right)$, the inlet $\left(T_{o i l_{2 F}}\right)$ and outlet $\left(T_{o i l_{1 F}}\right)$ oil temperatures and the outlet $\left(T_{a_{i i} F}\right)$ air temperature for a given power $(P)$ to be dissipated 
- Oil momentum balance

$$
R_{m o m, o i l}\left(T_{o i l_{1 F}}, T_{o i l_{2 F}}, Q_{o i l_{F}}\right)=0
$$

- Oil heat transfer

$$
R_{\text {ener,oil }}\left(T_{\text {oil }_{1 F}}, T_{\text {oil }_{2 F}}, Q_{o i l_{F}}\right)=0
$$

- Air heat transfer

$$
R_{\text {ener,air }}\left(T_{\text {air }_{2 F}}\right)=0
$$

- Heat transfer between oil-air

$$
R_{\text {hex }}\left(T_{o i l_{1 F}}, T_{\text {oil }_{2 F}}, T_{\text {air }_{2 F}}, Q_{o i l_{F}}\right)=0
$$

Also, another correlation equation to that used for the ONAN model in order to estimate the heat transfer coefficient for the fins working in forced convection. For the radiator which is analysed in this work, an average air velocity $\bar{U}_{a i r_{F}} \approx 3.27[\mathrm{~m} / \mathrm{s}]$ is adopted for the region blown by the fan, which is calculated as the average of the vertical air velocities measured in that region during the experiments (see section 4). This air velocity is an input data in the reduced model and it depends on the technical characteristics of the fan. Then, the average Reynolds number based on the length of the panel $\left(L_{p}\right)$ is given by

$$
\operatorname{Re}_{a i r_{L_{p}}}=\frac{\rho_{a i r} \cdot \bar{U}_{a i r_{F}} \cdot L_{p}}{\mu_{a i r}} \approx 3.84 \cdot 10^{5},
$$

for $L_{p}=1.8[\mathrm{~m}], \rho_{\text {air }}=1.1949\left[\mathrm{~kg} / \mathrm{m}^{3}\right]$ and $\mu_{\text {air }}=1.83 \cdot 10^{-5}[\mathrm{~Pa} \cdot \mathrm{s}]$. In (Churchill and Chu, 1975) and (Churchill, 1976) it is presented the following correlation for a mixed boundary layer (initially laminar followed by a turbulent boundary layer), where the average Nusselt number is written as

$$
\overline{\mathrm{Nu}}_{a_{\text {iir }}}=2 \cdot \frac{0.3387 \cdot \mathrm{Re}_{\text {air }}^{1 / 2} \cdot \operatorname{Pr}_{\text {air }}^{1 / 3}}{\left.\left(1+\left(0.0468 / \operatorname{Pr}_{a i r}\right)^{2 / 3}\right)^{1 / 4}\right)},
$$

and $\operatorname{Pr}_{a i r}$ is the air Prandtl number.

\subsection{Coupling natural and forced heat convection}

If it is considered that mixed heat convection conditions exist in the complete radiator, wherein $N_{1}$ fins work in natural convection and $N_{2}$ fins work in forced convection, as indicated by the respective pink and cyan zones in the radiator of Fig.1, the sets of equations corresponding to the natural and forced heat convection have to be coupled with a proper set of additional equations under the following assumptions. First, the total dissipated power must be the sum of the heat dissipated by the panels working in natural $\left(P_{N}\right)$ and forced $\left(P_{F}\right)$ convection

$$
P=P_{N}+P_{F}
$$

Also, the inlet oil temperature is assumed to be the same for all the fins, because they share the same pipe located at the top of the radiator and the temperature variation is small along the header (Nabati et al., 2009), wherewith

$$
T_{o i l_{2}}=T_{o i l_{2 N}}=T_{o i l_{2 F}}
$$




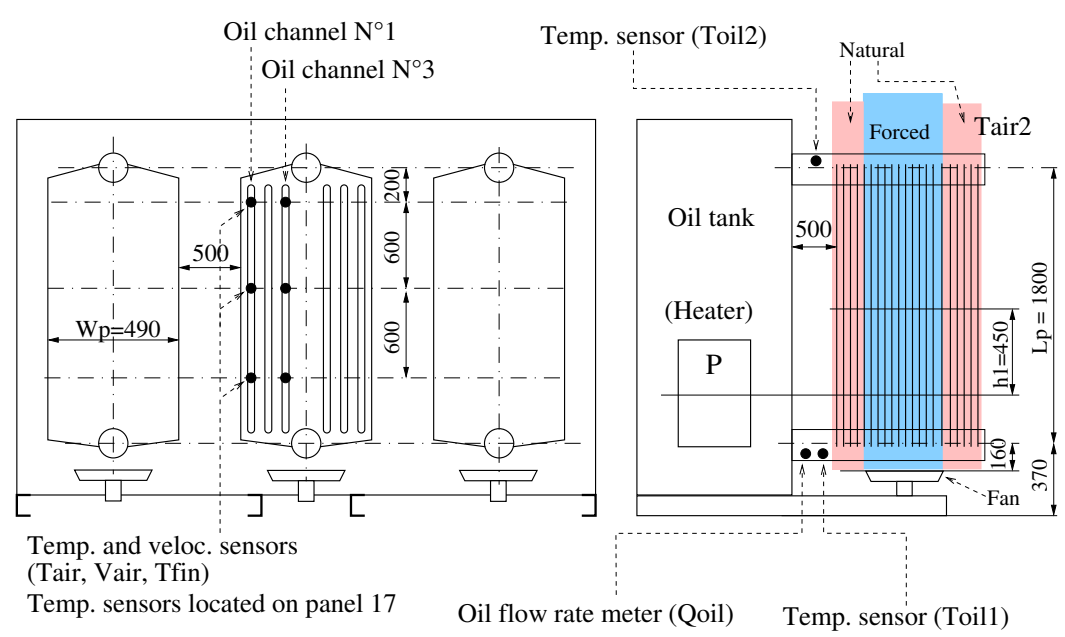

Figure 1: Schematic description of the experimental workbench and setup installation for ONAF flow tests (lenghts are in $\mathrm{mm}$ and out of scale).

Another condition to be satisfied is that the overall oil mass flow rate should be the sum of the mass flow rates of both parts

$$
Q_{o i l}=Q_{o i l_{N}}+Q_{o i l_{F}}
$$

and finally, it is considered that the outlet oil temperature is a weighted average of the outlet oil temperatures computed with the natural and forced convection models separately

$$
T_{o i l_{1}}=\frac{T_{o i l_{1 N}} \cdot Q_{o i l_{N}}+T_{o i l_{1 F}} \cdot Q_{o i l_{F}}}{Q_{o i l}}
$$

Under the previous constraints, the natural and forced convection subsystems are coupled and a set of nine non-linear equations with nine unknowns has to be solved. Finally, the extended reduced model considers the air properties to depend on the temperature. These properties are taken from (McQuillan et al., 1984) and they are interpolated using cubic splines (Bartels et al., 1998).

\subsection{Reduced model evaluation}

In order to evaluate the reduced model proposed in this work, a radiator manufactured by Tadeo Czerweny Company for its power transformers is analyzed. The radiator has $N_{p}=26$ panels and it is considered that 14 panels $\left(N_{1}\right)$ are working in forced convection and the other 12 panels $\left(N_{2}\right)$ are dissipating heat in natural convection condition. Each panel is assumed to have rectangular shape, with equivalents length $L_{p}=1.67[\mathrm{~m}]$ and width $W_{p}=0.521[\mathrm{~m}]$, in order to have the same total wet area $A_{p}=1.74\left[\mathrm{~m}^{2}\right]$ of the real panel. Each panel has six oil channels $\left(N_{c h a}=6\right)$ with cross sectional area $A_{c h a}=3.248 \times 10^{-4}\left[\mathrm{~m}^{2}\right]$ each one. The gap between the panels is $w_{\text {air }}=0.045[\mathrm{~m}]$ and the distance between the centerline of the radiator and that of the winding is $h_{1}=0.45[\mathrm{~m}]$. The radiator is made of carbon steel with thermal conductivity $k_{\text {steel }}=54[\mathrm{~W} /(\mathrm{m} \mathrm{K})]$ and thickness $t=1.25 \times 10^{-3}[\mathrm{~m}]$. The thermal conductivity $\left(k_{o i l}\right)$, density $\left(\rho_{o i l}\right)$ and specific heat $\left(C_{p_{o i l}}\right)$ of the oil are calculated using the 
following approximation presented in (Kim et al., 2013)

$$
\begin{aligned}
k_{\text {oil }} & =0.15217-7.16 \times 10^{-5} T_{\text {oil }_{2}},[\mathrm{~W} /(\mathrm{m} \mathrm{K})] \\
\rho_{\text {oil }} & =1067.75-0.6376 T_{\text {oil }_{2}},\left[\mathrm{Kg} / \mathrm{m}^{3}\right] \\
C_{p_{\text {oil }}} & =821.19+3.563 T_{\text {oil }_{2}},[\mathrm{~J} /(\mathrm{Kg} \mathrm{K})]
\end{aligned}
$$

The oil kinematic viscosity and its thermal expansion coefficient are taken from (Karsai et al., 1987) and they are interpolated using cubic splines. The temperature of the surrounding air is assumed to be $T_{a i r_{1}}=289[\mathrm{~K}]$. On the other hand, it is found in the experiments that the power dissipated by a single radiator in ONAF is approximately $P=14.9[\mathrm{~kW}]$ (see section 4). Solving the set of coupled non-linear equations with the above parameters the results shown in table 1 are obtained.

\begin{tabular}{|l|l|l|l|}
\hline$\tilde{\text { ÅU }}$ & Natural & Forced & Global \\
\hline$T_{\text {oil }}[\mathrm{K}]$ & 328.75 & 328.75 & 328.75 \\
\hline$T_{\text {oil }}[\mathrm{K}]$ & 314.1 & 308.25 & 310.35 \\
\hline$T_{\text {air } 2}[\mathrm{~K}]$ & 302.65 & 297.05 & - \\
\hline$Q_{\text {oil }}[\mathrm{lts} / \mathrm{min}]$ & 10.4 & 18.1 & 28.5 \\
\hline$P[\mathrm{~kW}]$ & 4.34 & 10.56 & 14.9 \\
\hline$U_{\text {air }}[\mathrm{m} / \mathrm{s}]$ & 0.93 & 3.27 & - \\
\hline$h\left[\mathrm{~W} /\left(\mathrm{m}^{2} \mathrm{~K}\right)\right]$ & 7.52 & 16.1 & - \\
\hline
\end{tabular}

Table 1: Characteristic parameters of the radiator computed with the ONAF reduced model.

The first column (Natural) refers to the results computed with the coupled reduced model for the radiator part that is dissipating heat in natural convection condition, the second column (Forced) refers to for the part of the radiator which is working in forced convection condition and the third column (Global) shows the results for the complete radiator.

\section{THREE-DIMENSIONAL SIMULATION OF THE RADIATOR IN ONAF MODE}

The CFD simulation is carried out with the HPC CFD Code Saturne ((EDF; Archambeau et al., 2004)) by solving the incompressible Navier-Stokes equations using a Finite Volume Method (FVM) (Versteeg and Malalasekra, 2007; Moukalled et al., 2015) with a transient analysis. A 3-D segregated solver is used with a SIMPLEC (Semi-Implicit Method for PressureLinked Equations Consistent) algorithm for the coupling between velocity and pressure (Jang et al., 1986) is used. A Second Order Linear Upwind (SOLU) method is considered for the spatial discretization and a second order scheme is used for the temporal integration. Since the heat transfer is very sensitive to the turbulence level developed within the air channels between the radiator panels and also to the thickness of the boundary layer (Churchill and Chu, 1975), special care is taken to generate the finite volume mesh in such a way as to use Large Eddy Simulation (Sagaut, 2006) with a Smagorinsky's (Smagorinsky, 91) eddy-viscosity using the Germano's model (Germano et al., 1991). Due to this fact and also to the geometrical complexity of the radiator, an hybrid structured - unstructured mesh with millions of cells is required for the discretization of the problem domain. As a consequence, the simulation is carried out using the computer cluster "Seshat" from CIMEC, equipped with an Intel $\AA$ Xeon $®$ CPU E5-2640 v2 @2.00GHz server and 69 Intel $囚$ Xeon $囚$ CPU E5-1620 v2 @ 3.7GHz computing nodes with 16GB RAM Micron@DDR3 $1600 \mathrm{Mhz}$, interconnected with an Infiniband@ network. 
A Boussinesq approximation is used to compute the driving force due to the temperature dependency of the density. The physical properties of the air are those used in the reduced model. As a result of the numerical simulation the total dissipated heat, the air velocity, the air temperature between the panels and the global and local heat transfer coefficients are obtained. In order to reduce the computational cost of the simulation avoiding the solution of a conjugated 3-D heat transfer problem for the complete radiator, the temperature distribution computed on a single radiator panel with the coupled 3-D thermo-fluid dynamic model presented in (Ríos Rodriguez et al., 2016) is used for setting that on each radiator panel.

The mesh is generated assuming that the panels have no thickness and the radiator is placed in a domain of size $\Delta x=1.25[\mathrm{~m}], \Delta y=3.0[\mathrm{~m}]$ and $\Delta z=2.0[\mathrm{~m}]$. The radiator and the fan relative positions with respect to the oil tank and the ground are the same than those existing in the experimental facility (see Fig.1). To attain a good quality mesh the domain is discretized with 6.5 Mcell hybrid mesh composed of tetrahedrons, hexas and pyramids. The mesh size exponentially grows from the wall to the bulk of the flow, with a mesh size at the wall equal to $h_{\text {wall }}=0.25[\mathrm{~mm}]$. The time step size used in the simulations is $\Delta t=1.25 \times 10^{-3}[\mathrm{~s}]$ and $10^{4}$ time steps were required to reach a steady heat transfer condition.

A cut of the mesh on a symmetry plane of the radiator is shown in Fig.(2). The top and lateral boundaries of the fluid domain are set as free inlet / outlet (opening boundary condition), allowing the air to escape through these regions. On the other hand, a wall boundary condition is set at the bottom to take into account the presence of the floor.

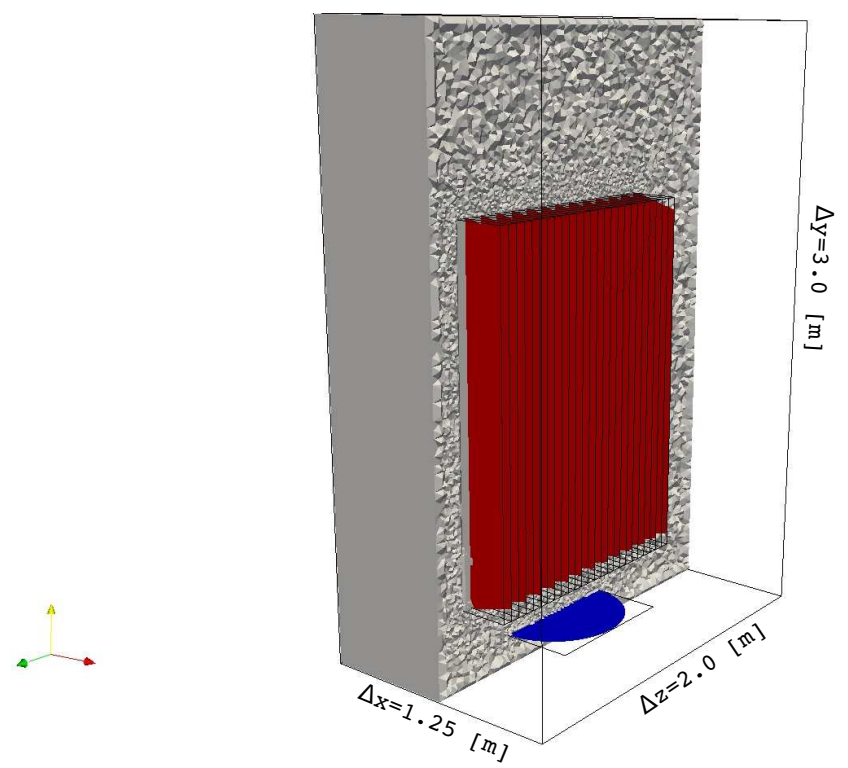

Figure 2: 3D domain for the complete radiator simulation and mesh detail around the radiator and between the panels. Fan boundary (blue), radiator panels (red) and fluid domain (grey).

The fan is modeled as a boundary region wherein it is allowed to set up the experimental fan curve as input through a polynomial with pressure curve coefficients which relate the pressure jump and velocity across the fan boundary. This kind of model predicts the global flow rate impelled by the fan but does not provide a detailed description of the flow through the fan blades. Additional parameters to be provided are the fan and hub radius. The pressure jump $\Delta p$ 
across the fan can be expressed as

$$
\Delta p=\sum_{n=1}^{N} C_{n} v^{n-1},
$$

where $C_{n}$ are the pressure curve coefficients and $v^{n-1}$ are the magnitudes of the local air velocity. This curve is provided by the fan manufacturer and it is fitted with a fourth degree polynomial (See Fig(3)). The characteristics of the fan are: rotation speed $\Omega=900$ [RPM], fan radius $R=350$ [mm] and hub radius $H_{r}=71[\mathrm{~mm}]$.

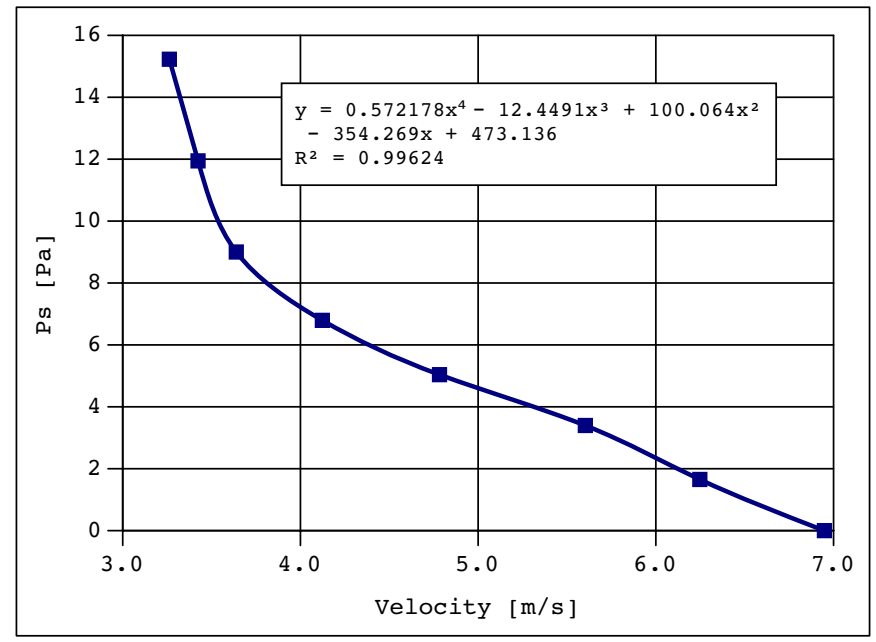

Figure 3: Fan curve for rotation speed $\Omega=900$ RPM.

The time averaged dissipated heat computed during the last 600 time steps is $P_{C F D}=13.4[\mathrm{Kw}]$ with a standard deviation of $0.2[\mathrm{Kw}]$. In Fig(4) it is shown a time averaged distribution of the heat transfer on each panel. It can be clearly observed the influence of the fan only in the middle section of the radiator, but it almost has no effect on the panels outside of that region. Only 14 panels are effectively blown by the fan. This conclusion will be also confirmed with the experimental measurements shown in section 4 . The power dissipated by the 12 panels working in ONAN condition is approximately $4.8[\mathrm{Kw}]$ and the power dissipated by the 14 panels blown by the fan is $8.6[\mathrm{Kw}]$.

The increase in both the heat transfer coefficient and the total dissipated power are due to an increase in the air velocity, as it is shown in Fig.(5). At the outlet of the fan the magnitude of the velocity is approximately $4.0[\mathrm{~m} / \mathrm{s}]$ and the average air speed at the outlet of the radiator is about $2.6[\mathrm{~m} / \mathrm{s}]$. This average velocity is slightly smaller than that experimentally measured.

Plotting the vertical air velocity at $200[\mathrm{~mm}]$ from the center of the top header it is also possible to determine the influence of the fan. In Fig.(6) it can be seen the time-averaged mean velocity between the panels (air channels) with square markers and the time-averaged minimum and maximum values in red for the CFD simulations. It is evident that the blown fins are those located right above the fan.

Also, it is important to compare the air temperature distribution between the radiator panels. From the reduced model the average air temperature in the channels not blown by the fan is $302.65[\mathrm{~K}]$ and that obtained from the CFD simulation is $300.5[\mathrm{~K}]$. The reduced model estimates a temperature of 297.05 [K] for the blown panels, whereas the CFD simulation value is 293.7 [K]. Although the CFD simulation provides a detailed description of the air temperature 

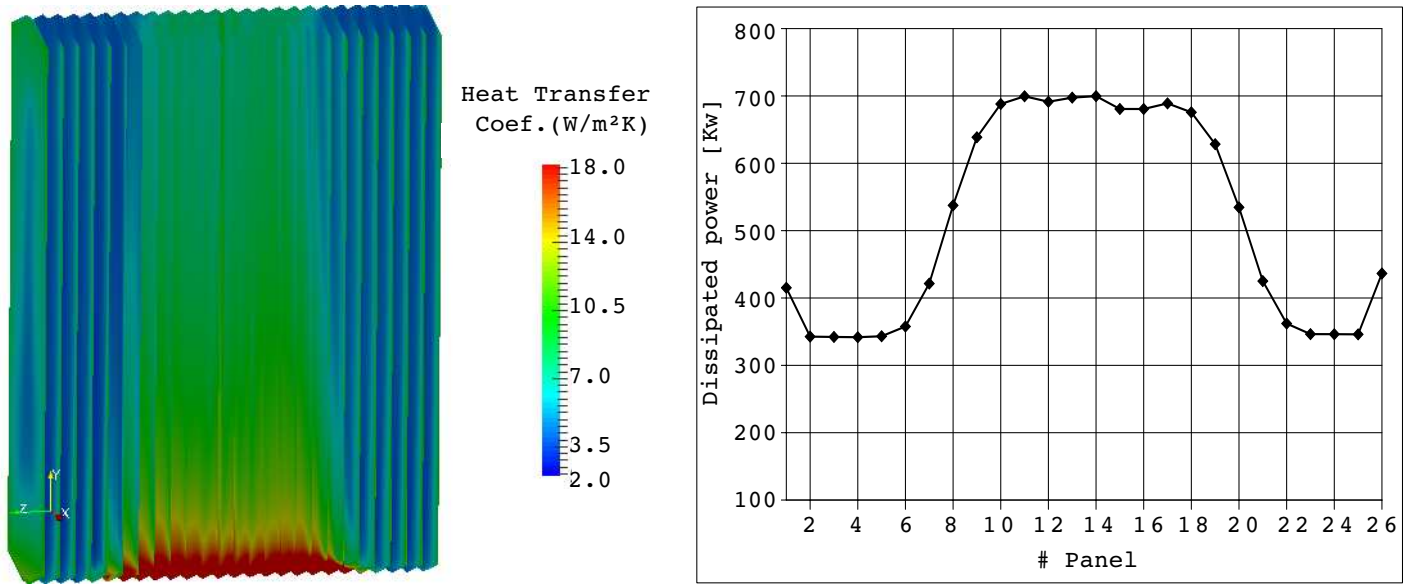

Figure 4: Time averaged heat transfer coefficient and dissipated power per panel.
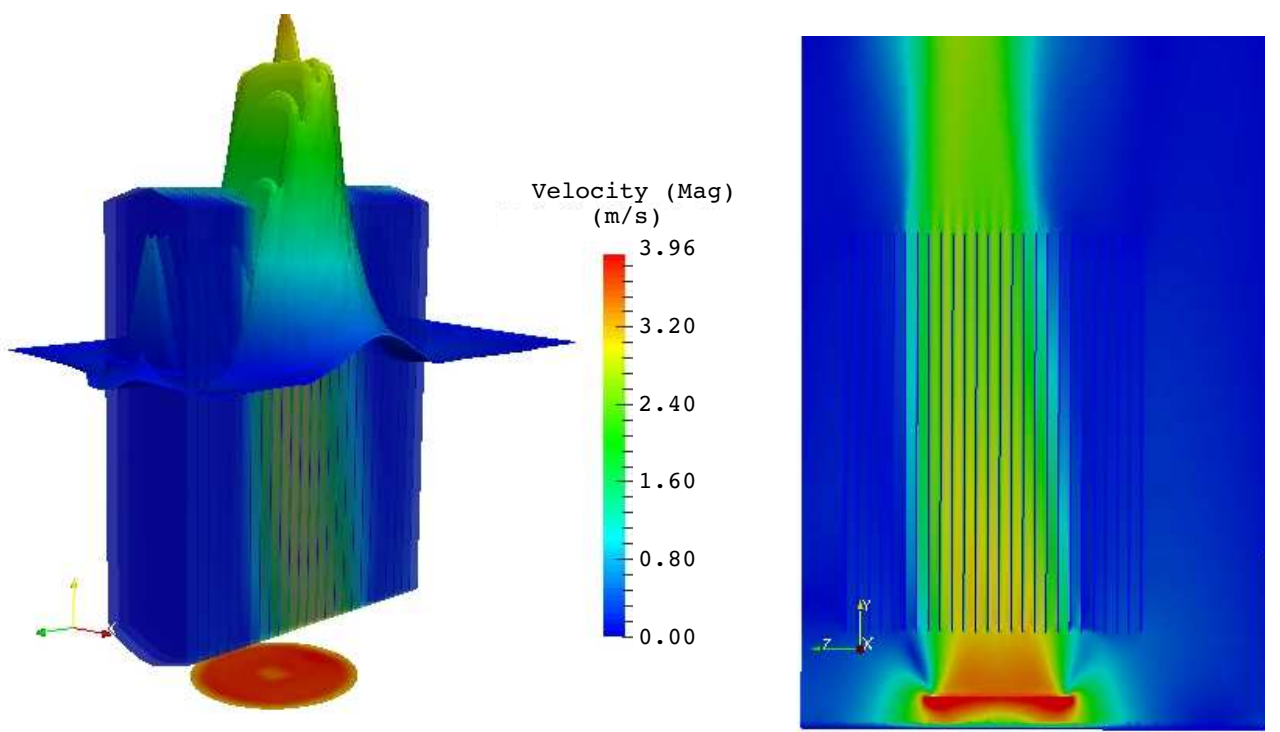

Figure 5: Magnitude of the air velocity.

inside each air channel, the reduced model predicts very well the average temperature at a very low computational cost, which is helpful during the design process.

Finally, table (2) summarizes the results already mentioned for a better comparison with those computed with the reduced model (table 1) and measured in the experiments (table 3 ).

\section{EXPERIMENTAL SETUP AND MEASUREMENTS}

The experimental measurements were realized on the workbench provided by Tadeo Czerweny, which is schematically shown in figure 1 . This workbench is equipped with three heaters, a 3000 Liters oil tank and three radiators, each one fitted with 26 panels of 1800 [mm] height and 490 [mm] width. More details about the workbench are described in (Ríos Rodriguez et al., 2016). For the ONAF test three fans were installed at $160[\mathrm{~mm}]$ under the center of the radiators bottom header. The fans have no casing and the rotation speed is 900 [RPM]. The dimensions and technical specifications of the fans are those described in section 3.

K-type thermocouples are installed at the top and bottom headers of the central radiator, halfway between the radiator and the oil tank (see figure 1), with the aim of measuring the oil 


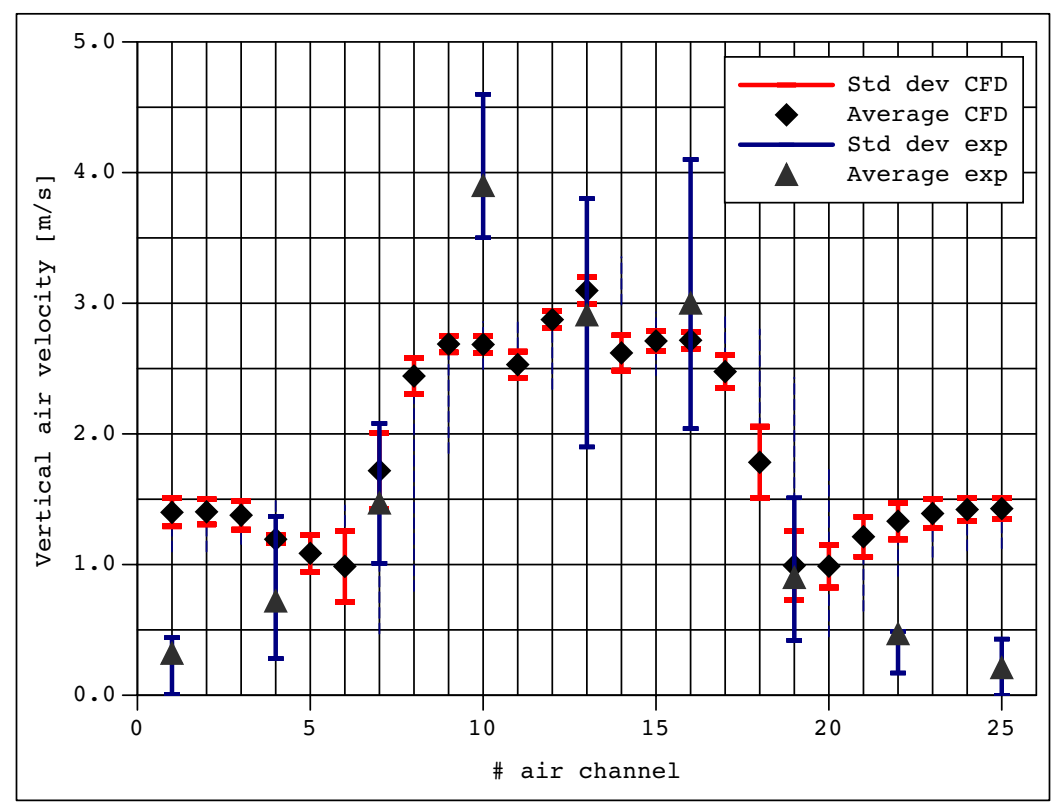

Figure 6: CFD and experimental time averaged air velocity magnitude along the radiator.
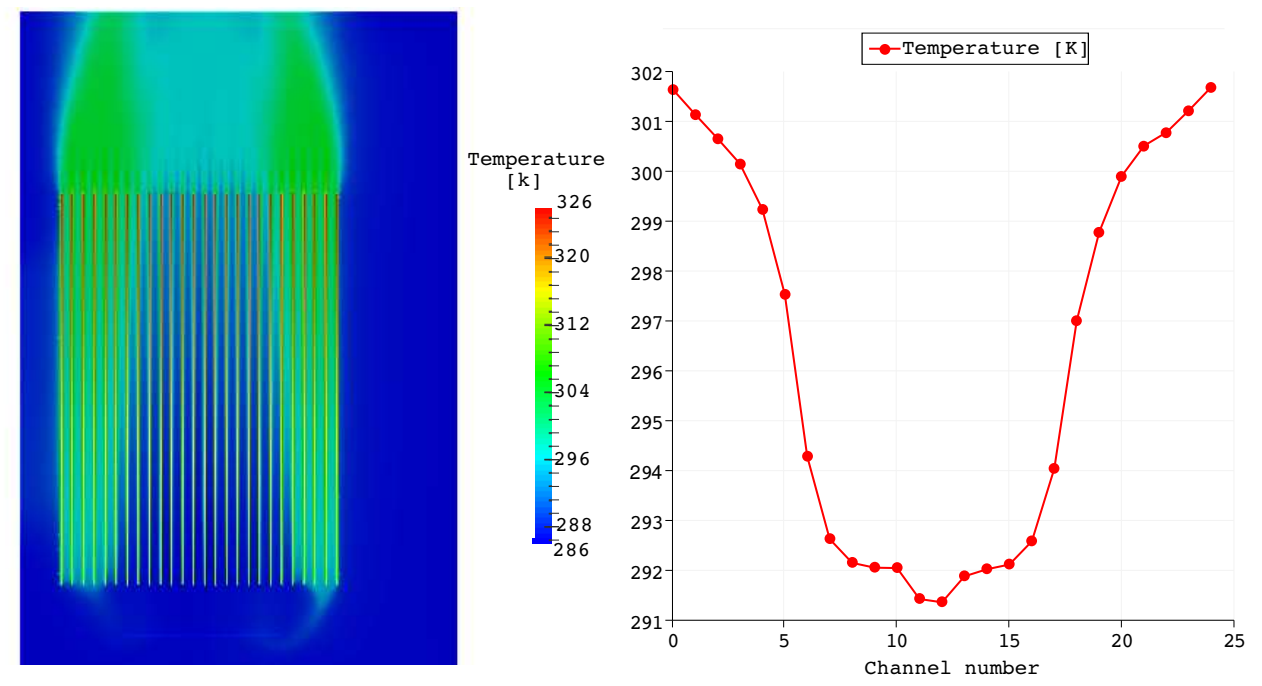

Figure 7: Radiator mid section air temperature distribution and air temperature at channels center.

temperature. The thermocouples have an accuracy of $2.2^{\circ} \mathrm{C}$ or $0.75 \%$ for the temperature range $>0^{\circ} \mathrm{C}$ to $1250^{\circ} \mathrm{C}$. On the other hand, the oil flow rate is registered at the return header, after the oil has cooled in the radiator. Finally, the air speed and temperature are measured at 200 [mm] from the center of the top header, widthwise of the radiator, with a hot-wire anemometer fitted with an $8[\mathrm{~mm}]$ diameter probe. The anemometer has a measuring range of $0.15[\mathrm{~m} / \mathrm{s}]$ to $3[\mathrm{~m} / \mathrm{s}]$ with an accuracy of $3 \%$ and $3.1[\mathrm{~m} / \mathrm{s}]$ to $30[\mathrm{~m} / \mathrm{s}]$ with an accuracy of $3 \%$ and an air temperature range of $-20^{\circ} \mathrm{C}$ to $80^{\circ} \mathrm{C}$ with an accuracy of $0.4 \%$.

The workbench is surrounded by walls, not drawn in figure 1 in order to avoid air currents to influence the air speed measurements and the oil tank is wrapped with a thermal insulation to avoid heat losses.

The experimental test is carried out in accordance to the following procedure in order to com- 


\begin{tabular}{|l|l|l|l|}
\hline$\tilde{A} \dot{U}^{\circ}$ & Natural & Forced & Global \\
\hline$T_{\text {air }}[\mathrm{K}]$ & 300.5 & 293.7 & - \\
\hline$P[\mathrm{~kW}]$ & 4.8 & 8.6 & 13.4 \\
\hline$U_{\text {air }}[\mathrm{m} / \mathrm{s}]$ & 1.24 & 2.6 & - \\
\hline
\end{tabular}

Table 2: Characteristic parameters of the radiator computed with the CFD simulation.

pare the results of the measurements with those obtained with the CFD simulations presented in section 3 and with those calculated with the reduced model presented in section 2. First, the workbench is taken to steady state regime in ONAN, considering that the three heathers are supplied with $10[\mathrm{~kW}]$ each. Then, the fans are turned on at $900 \mathrm{rpm}$ and the power supplied by the heaters is adjusted in order to keep constant the oil temperature at the inlet of the radiator to the value registered in steady state ONAN conditions $\left(T_{o i l_{2}}=327.51 \mathrm{~K}\right)$. The oil temperature at the outlet $\left(T_{o i l_{1}}\right)$ and the oil flow rate are measured to calculate the dissipated power of the radiator in that steady state ONAF condition. The results obtained with the former procedure are presented in table 3 , where $T_{a i r_{2}}$ and $U_{\text {air }}$ are mean time averaged quantities.

\begin{tabular}{|l|l|l|l|}
\hline$\tilde{\text { ÅU }}$ & Natural & Forced & Global \\
\hline$T_{\text {oil }_{2}}[\mathrm{~K}]$ & - & - & 327.5 \\
\hline$T_{\text {oil }_{1}}[\mathrm{~K}]$ & - & - & 311.6 \\
\hline$T_{\text {air }_{2}}[\mathrm{~K}]$ & 297.9 & 295.9 & - \\
\hline$Q_{\text {oil }}[\mathrm{lts} / \mathrm{min}]$ & - & - & 33 \\
\hline$P[\mathrm{~kW}]$ & - & - & 14.9 \\
\hline$U_{\text {air }}[\mathrm{m} / \mathrm{s}]$ & 0.68 & 3.27 & - \\
\hline
\end{tabular}

Table 3: Experimentally measured parameters of the workbench for steady state ONAF conditions.

The vertical air velocity distribution measured for various air channels at $200[\mathrm{~mm}]$ from the top header center is shown in Fig.(6) (i.e. the air channels are numbered following the same order as the radiator panels - see Fig.1). Therein the yellow dots denote the time-averaged mean values registered at the center of the channels and the blue bars represent the time averaged minimum and maximum values measured during a time lapse of approximately 180 seconds. It is apparent that the influence region of the fan is limited only to the 15 panels located directly above, which is the same behavior observed in the numerical simulation results, although there are some differences in the air velocities for the regions in natural convection.

Finally, table (4) shows a comparison among the results computed with the reduced analytical model against those measured in the experiments and computed with the CFD simulation. Therein, for example, the relative error in the oil temperature $\Delta T_{\text {oil }}$ is defined as $\left|e_{\Delta T_{\text {oil }}}\right|=\left|\Delta T_{\text {oil (RM) }}-\Delta T_{\text {oil (Exp })}\right| /\left|\Delta T_{\text {oil (Exp) }}\right|$ if it is in the Reduced vs. Experimental column or as $\left|e_{\Delta T_{\text {oil }}}\right|=\left|\Delta T_{\text {oil (RM) }}-\Delta T_{\text {oil }(C f d)}\right| /\left|\Delta T_{\text {oil }(C f d)}\right|$ if it is in the Reduced vs. CFD column.

When analyzing the results computed with the reduced model in table 4 against those obtained in the experiments, it should be considered that there are some uncertainties in the temperature, oil flow rate and air velocity measurements, due to the accuracy of the instruments. On the other hand, the reduced model is based on a set of coupled nonlinear residual equations, and since it uses semi-analytical correlations and also experimental values as input data, it is very difficult to trace back which are the origins of the biggest uncertainties in the computed values. 


\begin{tabular}{lllllllll}
\hline & \multicolumn{3}{c}{ Reduced model vs. Experimental } & & \multicolumn{3}{c}{ Reduced model vs. CFD } \\
\cline { 2 - 3 } & Natural & Forced & Global & & Natural & Forced & Global \\
\hline$\left|e_{\Delta T_{\text {oil }}}\right|$ & - & - & - & 0.157 & & - & - & - \\
$\left|e_{T_{\text {air }}}\right|$ & 0.016 & 0.004 & - & & 0.007 & 0.011 & - \\
$\left|e_{Q_{\text {oil }}}\right|$ & - & - & - & 0.136 & & - & - & $(2)$ \\
$\left|e_{P}\right|$ & - & - & $(1)$ & & 0.096 & 0.228 & $0.112(1)$ \\
$\left|e_{U_{\text {air }}}\right|$ & 0.367 & $(1)$ & - & & 0.456 & & 0.205 & - \\
\hline
\end{tabular}

Table 4: Comparison among the reduced analytical model, experimental and CFD results. (1) Experimental value used as input in the reduced model. (2) Experimental value used as input in the CFD model.

For example, the reduced model considers a correlation for computing the Nusselt number in the forced convection air zone, which depends on the air velocity. Since the air velocity used in the reduced model is the average of that measured in the experiments in the fan region and due to the uncertainties in the experimental values shown in fig.(6) and also in the accuracy of the correlation given by eq.(11), it is expected that this value could introduce some errors in the results computed with the reduced model.

On the other hand, if the air velocity in the fan region of the CFD simulation is analyzed, it should be considered that the fan is modeled as a boundary region with the aim of reducing computational costs. This simplification could also introduce errors in the CFD results because, as it is already mentioned in section 3, this fan model predicts the global flow rate impelled by the fan but does not provide a detailed description of the flow through the fan blades. As a consequence, the details of the air flowing into the radiator are not considered in the simulations and the exact details of the flow turbulence between the panels might not be accurately predicted. The simulation of such features of the flow should improve the accuracy of the CFD results in that region, but at a very high computational cost. Also, the reduced model equations do not consider local and three dimensional effects in the air flow through the panels and barely take into account the transition from laminar to turbulent flow considering parallel flow between flat plates.

\section{CONCLUSIONS}

A reduced model to simulate and analyze the thermo-fluid dynamic behavior of a power transformer working in ONAF conditions was introduced in this work. The model assumes a mixed heat convection framework, wherein a fraction of the radiator panels is dissipating heat to the air by forced convection and the other fraction is performing this by natural convection. The model solves a set of coupled non-linear equations for natural and forced heat convection which is obtained from applying the energy and momentum conservation laws to the air and the oil, as well as the heat conduction through the panel. Also, semi-empirical correlations and appropriate coupling conditions between both convection models are applied. The experimental measurements and the CFD results show that the reduced model predicts with acceptable accuracy the values of the most important design variables, i.e., oil flow rate, oil temperature, air temperature and mean velocity, at a reduced computational cost. This feature of the reduced model would allow to run parametric studies or introduce an optimization procedure, for example, in the shape and size of the oil channels or in the shape, size or separation distance between radiator panels. As a consequence, design engineers could consider this model as a valuable 
calculation tool. Of course, if localized effects like the oil velocity or temperature distributions within a channel are required to be analyzed, only CFD simulations and experiments on a workbench are able to provide detailed information but also at higher costs. Finally, the air velocity distribution along the radiator both computed in the CFD simulations and experimentally measured shows that the cooling produced by the fan which is tested in the workbench is not efficient since approximately half of the radiator panels are not blown. Some kind of diffuser together with a better design of the blades as well as the usage of smaller and evenly distributed fans may improve the efficiency in the cooling if vertical blowing is assumed. On the other hand, the horizontal blowing already explored in (Paramane et al., 2014), considering an offset of the fans, is also worth to be analyzed.

\section{ACKNOWLEDGMENTS}

This work has received financial support from Consejo Nacional de Investigaciones Científicas y Técnicas (CONICET, Argentina, grant PIP 11220150100588CO), Universidad Nacional del Litoral (UNL, Argentina, grant CAI+D 2011-01-00012-LI, CAI+D-501-201101-00233-LI), Agencia Nacional de Promoción Científica y Tecnológica (ANPCyT, Argentina, grants PICT 2660-14, PICT-E 0191-14, PICT 0938-13, PICT-2015-2904), Secretaría de Ciencia, Tecnología y Producción para la Defensa (grant PIDDEF-4/14), Agencia Santafesina de Ciencia, Tecnología e Innovación (ASACTEI, Argentina, grant 00010-18-2014).

This work was performed with Free Software Foundation/GNU-Project resources like GNULinux OS, GNU-GFortran, GNU-Octave, GNU-Git and GNU-GIMP, as well as other Open Source resources such as NETGEN, Para-View, Xfig and LTEX.

Also, the authors made use of the computer cluster "Seshat", which is part of the computer center of CIMEC. This computer center is integrated to the Sistema Nacional de Computación de Alto Desempe Ãso (SNCAD), which is a joint project of Ministerio de Ciencia, Tecnología e Innovación Productiva (MINCyT) and Consejo Interinstitucional de Ciencia y Tecnología (CICyT).

The authors would also like to acknowledge Tadeo Czerweny S.A company, Santa Fe, Argentina for providing human resources, the benchmark and other facilities for realizing the experimental measurements. Finally, a special acknowledgement is dedicated to Engineer José Ríos for giving his support and experience to carry out the experimental measurements. 


\section{REFERENCES}

Archambeau F., MÃl'chitoua N., and Sakiz M. Code saturne: a finite volume code for the computation of turbulent incompressible flows-industrial applications. International Journal of Finite Volume, 1:1-62, 2004.

Bartels R.H., Beatty J.C., , and Barsky B.A. An Introduction to Splines for Use in Computer Graphics and Geometric Modeling. Morgan Kaufmann, 1998.

Churchill S. A comprehensive correlating equation for forced convection from flat plates. AICHE J., 22:264âĂŞ268, 1976.

Churchill S. and Chu H. Correlating equations for laminar and turbulent free convection from a vertical plate. Int. Journal Heat Mass Tran, 18, 1975.

EDF C. Code Saturne an open source cfd software. http://code-saturne.org, ????

El Wakil N., Chereches N., and Padet J. Numerical study of heat transfer and fluid flow in a power transformer. International Journal of Thermal Sciences, 45:615-626, 2006.

Gastelurrutia J., Ramos J.C., Larraona G.S., Rivas A., Izagirre J., and del Río L. Numerical modeling of natural convection of oil inside distribution transformers. Applied Thermal Engineering, 31:493-505, 2011.

Germano M., Piomelli U., Moin P., and Cabot W. A dynamic subgrid-scale eddy viscosity model. Physics of Fluids A, 3:1760-1765, 1991.

Jang D., Jetli R., and Acharya S. Comparison of the PISO, SIMPLER, and SIMPLEC algorithms for the treatment of the pressure-velocity coupling in steady flow problems. Numerical Heat Transfer, 10:209-228, 1986.

Karsai K., Kerenyi D., and Kiss L. Large Power Transformers. Elsevier Company, 1987.

Kim M., Cho S., and J. K. Prediction and evaluation of the cooling performance of radiators used in oil-filled power transformer applications with non-direct and direct-oil-forced flow. Experimental Thermal and Fluid Science, 44:392-397, 2013.

McQuillan F., Culham J., and Yovanovich M. Properties of dry air at one atmosphere. Microelectronics Heat Transfer Lab, University of Waterloo, 1984.

Moukalled F., Mangani L., and Darwish M. The Finite Volume Method in Computational Fluid Dynamics. Springer International, 2015.

Nabati H., Mahmoudi J., and Ehteram A. Heat transfer and fluid flow analysis of power transformer's cooling system using cfd approach. Chemical Product and Process Modeling, 43, 2009.

Paramane S., Joshi K., Van der Veken W., and Sharma A. Cfd study on thermal performance of radiators in a power transformer: Effect of blowing direction and offset of fans. Power Delivery, IEEE Transactions on, 29:2596-2604, 2014.

Paramane S., Van der Veken W., and Sharma A. A coupled internal-external flow and conjugate heat transfer simulations and experiments on radiators of a transformer. Applied Thermal Engineerig, 103:961-970, 2016.

Ríos Rodriguez G., Garelli L., Storti M., Granata D., Amadei M., and Rossetti M. Numerical and experimental thermo-fluid dynamic analysis of a power transformer working in onan mode. Applied Thermal Engineering, 112:1271-1280, 2016.

Sagaut P. Large Eddy Simulation for Incompressible Flows: An Introduction, volume 4. Series Scientific Computation, 2006.

Smagorinsky J. General circulation experiment with the primitive equation. i. the basic experiment. Monthly Weather Review, 1963:99-165, 91.

Torriano F., Picher P., and Chaaban M. Numerical investigation of $3 \mathrm{~d}$ flow and thermal effects 
in a disc-type transformer winding. Applied Thermal Engineering, 40:121-131, 2012.

Tsili M., Amoiralis E., Kladas A., and Souflaris A. Power transformer thermal analysis by using an advanced coupled $3 \mathrm{~d}$ heat transfer and fluid flow fem model. International Journal of Thermal Sciences, 53:188-201, 2012.

Vecchio R., Poulin B., Feeney M., Feghali P., Shah D., Ahuja R., and Shah D. Transformer Design Principles: With Applications to Core-Form Power Transformers. CRC Press, 2001.

Versteeg H. and Malalasekra W. An Introduction to Computational Fluid Dynamics: The Finite Volume Method. Prentice Hall, 2007. 